Protestantismo em Revista é licenciada sob uma Licença Creative Commons.

http:/ / dx.doi.org/10.22351/nepp.v44i2.3709

\title{
Intolerância religiosa, desinformação e discriminação no cenário brasileiro: significados, repercussões e possibilidades de mudança
}

\author{
Religious intolerance, disinformation and discrimination in the Brazilian scenario: \\ meanings, repercussions and possibilities of change
}

Gilmário Kassandro Xavier Pinheiro* Danielle Ventura de Lima Pinheiro**

\begin{abstract}
Resumo
A intolerância religiosa no contexto brasileiro é tema de reflexão fundamental para as áreas de ciências das religiões e de direitos humanos por revelar uma faceta atual da sociedade, principalmente no que diz respeito às diversas formas de discriminações contra as religiões de matriz africana. Assim, o presente estudo voltar-se-á para este tema pensando nas leis brasileiras e naquelas que são reconhecidas mundialmente, bem como se amparando na análise de alguns autores que trazem esta reflexão em seus respectivos estudos. Pretende-se, a partir desta análise, chamar a atenção da sociedade sobre as leis que visam promover a liberdade de crença, a tolerância religiosa e o respeito à pluralidade atual. Como resultados, destacamos a análise de algumas terminologias como discriminação, minorias e intolerância religiosa; o aparato legal atual nos ajuda a compreender o cenário religioso brasileiro, cujas leis precisam ser aplicadas para garantir o respeito à pluralidade religiosa tão característica do país. Aponta-se, ainda, como a Escola pode dar a sua contribuição ao promover o respeito às diferenças desde a infância, a partir das abordagens sugeridas por alguns estudiosos para o Ensino Religioso.
\end{abstract}

Palavras-chave

Tolerância religiosa. Liberdade de crença. Pluralidade.

Abstract

[Texto recebido em janeiro de 2018 e aceito em julho de 2018, com base na avaliação cega por pares realizada por pareceristas ad hoc]

O presente artigo foi ampliado e repensado pelos autores e foi fruto de um estudo desenvolvido por Gilmário Pinheiro em seu Trabalho de Conclusão de Curso da Especialização em Ciências da Religião pela FAVENI. Acrescentou-se aqui, em especial, como a Escola pode contribuir para que se promova a cultura da paz após muitas discussões sobre o sentido da intolerância religiosa atual.

* Graduado em História. Graduando em Pedagogia. Especialista em Ciências da Religião. E-mail: gilmariokassandro@yahoo.com.br

** Graduada em História. Graduada em Pedagogia. Mestra em Ciências das Religiões. Doutora em Ciências das Religiões. Doutora em Educação (UFPB). E-mail: daniellyventura@hotmail.com 


\begin{abstract}
Religious intolerace in the Brazilian context is the theme of fundamental reflection for the areas of sciences of religions and of human rights since it reveals the current facet of society, mainly with regard to the various forms of discriminations against the religions of the African matrix. Thus, this study turns to this theme thinking about the Brazilian laws and those which are globally recognized, as well as supporting itself on the analysis of some authors who bring this reflection in their respective studies. Based on this analysis the intent is to call the attention of society about laws which aim at promoting freedom of belief, religious tolerance and respect toward current plurality. As results we highlight the analysis of some terminologies such as discrimination, minorities and religious intolerace; the current legal aparatus helps us understand the Brazilian religious scenario, the laws of which need to be applied to guaranteee the respect for religious plurality so characteristic of the country. It also points out how the School can give its contribution when it promotes respect toward differences from childhood on, based on the approach suggested by some researchers on Religious Education.
\end{abstract}

\title{
Keywords
}

Religous intolerace. Freedom of belief, Plurality.

\section{Introdução}

O termo intolerância significa "qualidade de intolerante, falta de tolerância". O dicionário consultado remete ao termo intolerantismo como: "1. Doutrina que tem por princípio a intolerância religiosa. 2. Sistema daqueles que não admitem opiniões divergentes das suas, em questões, sociais, politicas ou religiosas“. ${ }^{1}$

Logo, a intolerância religiosa pode ser entendida por um conjunto de ideias e ações de ataque a diferentes crenças e religiões. Dependendo da gravidade, as ofensas podem tornar-se uma opressão. Tal ato pode ser caracterizado como um delito que agride a liberdade e a dignidade humana, por ser um crime de incentivo ao ódio. A perseguição religiosa é de extrema gravidade e costuma ser reconhecida pelo ataque, discriminação e até mesmo por atos que atentam contra a vida de um determinado grupo que tem em comum uma religião diferenciada.

As liberdades de expressão e de culto são asseguradas pela Declaração Universal dos Direitos Humanos como se pode observar a seguir:

Todo ser humano tem direito à liberdade de pensamento, consciência e religião; este direito inclui a liberdade de mudar de religião ou crença e a liberdade de manifestar essa religião ou crença, pelo ensino, pela prática,

1 FERREIRA, Aurélio Buarque de Holanda. Dicionário Aurélio básico da Língua Portuguesa. Rio de Janeiro: Nova Fronteira, 1988. p. 367. 
pelo culto e pela observância, isolada ou coletivamente, em público ou em particular. $^{2}$

A profundidade da Declaração Universal dos Direitos Humanos nos faz refletir sobre a emergência de propagá-la, uma vez que esta profundidade gera uma reflexão sobre a necessidade de se garantir a todos a liberdade de crença na esfera pública e privada. Corroborando com isso, a Constituição Federal do Brasil ressalta que: “[...] é inviolável a liberdade de consciência e de crença, sendo assegurado o livre exercício dos cultos religiosos e garantida, na forma da lei, a proteção aos locais de culto e a suas liturgias". ${ }^{3}$

A inviolabilidade da liberdade de crença e de consciência, prevista pela Carta Magna, requer ampla divulgação para que as pessoas se sensibilizem e respeitem tanto as pessoas e seus credos como também os locais de culto.

Vale esclarecer que a intolerância religiosa é diferente da crítica religiosa, pois todos têm o direito de criticar preceitos e aconselhamentos de um seguimento religioso, até porque, são assegurados pela liberdade de opinião e expressão, todavia essa crítica deve ser feita de forma que não haja desrespeito ao grupo religioso a que é direcionada a opinião. As críticas às religiões são corriqueiras sendo, de certa forma, essenciais para o debate democrático, uma vez que a religião tem papel fundamental na vida político-social e cultural da sociedade brasileira.

Portanto, o presente trabalho visa apresentar os prejuízos da intolerância religiosa, destacando as leis que asseguram a liberdade de crença e a intolerância contra os cultos de matriz africana, por serem muito observados no contexto brasileiro. Para tanto, a observação de algumas leis e análise de autores que se voltam para esta discussão serão fundamentais para o presente estudo. Traremos ainda a Escola como capaz de dirimir tais atitudes de intolerância caso o discente tenha a oportunidade de debater sobre tal temática desde a sua infância.

\section{Crenças de matriz africana: um ataque constante?}

[...] a intolerância religiosa se converteu numa das principais causas de perseguição das minorias no mundo. Assim, "a intolerância é o novo

2 ORGANIZAÇÃO DAS NAÇÕES UNIDAS. Declaração Universal dos Direitos Humanos (1948). Artigo 18. Disponível em: < http://www.dudh.org.br/wp-content/uploads/2014/12/dudh.pdf>. Acesso em: 19 jul. 2015.

3 BRASIL. Casa Civil. Subchefia para Assuntos Jurídicos. Constituição da República do Brasil. Art. 5, VI. Disponível em: <http://www.planalto.gov.br/ccivil_03/constituicao/constituicao.htm>. Acesso em: 25 set. 2015. 
racismo e muitas comunidades que enfrentaram discriminações raciais durante décadas são agora perseguidas por causa de sua religião". ${ }^{4}$

Por minoria, entende-se aqueles que estão em desvantagem a um determinado grupo e que, geralmente, recebem um tratamento discriminatório pela maioria. ${ }^{5}$ Assim, podem ser considerados como grupos minoritários os adeptos das religiões de matrizes africanas. Estas foram incorporadas à cultura brasileira desde a época que chegaram os primeiros negros vindos da África para serem escravizados e encontraram em sua religiosidade uma forma de preservar suas tradições. ${ }^{6}$

Sobre as religiões de matrizes africanas, podemos indagar até que ponto esses preconceitos em relação a estas religiões refletem apenas um elemento constitutivo da formação de suas identidades, sendo, portanto algo que as diferencia, ou algo que pode conduzir à intolerância, pois podem se caracterizar como um estigma que, arraigado nos valores da modernidade, reitera exclusões históricas.

Segundo Silva, a intolerância religiosa é:

Uma expressão que descreve atitudes fundadas nos preconceitos caracterizados pela falta de respeito às diferenças de credos religiosos praticados por terceiros, podendo resultar em atos de discriminações violentas dirigidas a indivíduos específicos ou em atos de perseguição religiosa, cujo alvo é a coletividade. Essa perseguição religiosa vem, nas últimas décadas, configurando-se em verdadeira batalha espiritual, ameaçando os padrões de uma sociedade alicerçada na ética, na liberdade, na democracia e na cultura da paz. ${ }^{7}$

A análise de Silva ${ }^{8}$ nos dá um panorama da gravidade da situação do país em relação ao cenário de intolerância religiosa e as suas repercussões negativas. Associar tal situação alarmante ao aparato legal que criminaliza tais atitudes permite uma visão crítica em relação ao que tem sido feito para se contornar tais situações e diminuir as demonstrações evidentes de intolerância religiosa no cenário atual, atentando especificamente para o Brasil.

4 ROCHA, José G. A intolerância religiosa e religiões de matrizes africanas no Rio de Janeiro. Revista África e Africanidades, ano IV, n. 14/15, ago./nov. 2011. à p. 1. Disponível em: <www.africaeafricanidades.com>. Acesso em: 05 jul. 2015.

5 CHAVES, L. G. Mendes. Minorias e seu estudo no Brasil. Revista de Ciências Sociais, Fortaleza, v. 1, n. 1, p. 149-168, 1970. Disponível em: <http://www.repositorio.ufc.br/handle/riufc/4487>. Acesso em: 01 ago. 2017.

6 SOUZA, Laura M. O diabo e a Terra de Santa Cruz. São Paulo: Companhia das Letras, 1986.

7 SILVA, M. V. "Liberdade, Democracia e Intolerância Religiosa”. In: SANTOS, I.; ESTEVES FILHO, A. (Orgs). Intolerância Religiosa X Democracia. Rio de Janeiro: CEAP, 2009. p. 125-143. à p. 128.

8 SILVA, 2009. 
A Lei n. 12.288/2010, por exemplo, que institui o Estatuto da Igualdade Racial, ${ }^{9}$ altera os mecanismos já existentes na Constituição referentes à discriminação de raça, crimes de ódio e exclusão social, e busca efetivar a igualdade de oportunidades da população negra, defender os direitos étnicos individuais e combater formas de intolerância étnica, procurando difundir o respeito às religiões de matriz africana.

Do ponto de vista da origem, pode-se afirmar que tal intolerância está relacionada ao sistema de convicção religiosa, nas próprias crenças dos indivíduos ou mesmo na incapacidade do indivíduo de compreender as crenças e práticas religiosas diferentes da sua e consequentemente, admitir o seu direito à existência. ${ }^{10}$

As experiências, no cotidiano, das múltiplas práticas de intolerância religiosa interferem diretamente nos processos de interação social das pessoas que professam a sua fé nas religiões de matrizes africanas. ${ }^{11}$

Por mais que o Brasil seja um país latino, não podemos deixar de levar em consideração a influência africana e a sua importância na implementação dos cultos afros.

O Brasil é um país livre no que diz respeito às práticas religiosas individuais, considerando as múltiplas manifestações existentes de norte a sul. A livre prática religiosa envolve por sua vez, a livre escolha religiosa.

\section{Discriminação religiosa é crime}

Conforme a Lei n. 9.459/97, ninguém pode ser discriminado em razão de credo religioso. ${ }^{12}$ O Supremo Tribunal Federal já decidiu que a discriminação religiosa é uma espécie de prática de racismo. Isto significa que o crime de discriminação religiosa é inafiançável (o acusado não pode pagar fiança para responder em liberdade) e imprescritível (o acusado pode ser punido a qualquer tempo). A pena para o crime de discriminação religiosa pode chegar a 5 anos de reclusão.

São orientações presentes no site do Senado Federal ${ }^{13}$ que a vítima se direcione a uma Delegacia de Polícia para registrar ocorrência em caso de discriminação religiosa. O

9 BRASIL. Casa Civil. Subchefia para Assuntos Jurídicos. Lei n. 12.288, de 20 de julho de 2010. Estatuto da Igualdade Racial. Disponível em: <http://www.planalto.gov.br/ccivil_03/_ato20072010/2010/lei/112288.htm>. Acesso em: 02 out. 2015.

10 ROCHA, 2011.

11 Sobre estas experiências de intolerância religiosa, veja-se o artigo de: TOKARNIA, Mariana. Negros e religiões africanas são os mais discriminados, mostra Disque $100 . \quad$ Disponível em: <http:/ /agenciabrasil.ebc.com.br/direitos-humanos/noticia/2015-07/negros-e-religioes-africanas-saoos-que-mais-sofrem-discriminacao>. Acesso em: 10 set. 2015.

12 BRASIL. Casa Civil. Subchefia para Assuntos Jurídicos. Lei n. 9.459, de 13 de maio de 1997. Disponível em: <http://www.planalto.gov.br/ccivil_03/leis/L9459.htm>. Acesso em: 01 out. 2015.

13 STECK, Juliana. Intolerância religiosa é crime de ódio e fere a dignidade. Disponível em <http://www12.senado.gov.br/jornal/edicoes/2013/04/16/intolerancia-religiosa-e-crime-de-odio-efere-a-dignidade>. Acesso em: 10 jul. 2015. 
Delegado de Polícia tem o dever de instaurar inquérito, colher provas e enviar o relatório para o Judiciário, a partir disso terá início o processo penal.

A liberdade de expressão constitui um dos fundamentos essenciais de uma sociedade democrática e compreende não somente as informações consideradas como inofensivas, indiferentes ou favoráveis, mas também aquelas que possam causar transtorno, resistência, inquietar as pessoas, pois a Democracia somente existe a partir da consagração do pluralismo de idéias e pensamentos, da tolerância de opiniões e do espírito aberto ao diálogo. ${ }^{14}$

Entretanto, quando tais manifestações giram em torno da religiosidade, essa liberdade de expressão pode ocasionar ações preconceituosas de hostilidade para com a religião do outro.

A concepção exposta na Declaração de Princípios sobre a Tolerância, aprovada pela Conferência Geral da Unesco, em Paris, em 1995, afirma que:

A tolerância é o respeito, a aceitação e a apreço da riqueza e da diversidade das culturas de nosso mundo, de nossos modos de expressão e de nossas maneiras de exprimir nossa qualidade de seres humanos. É fomentada pelo conhecimento, a abertura de espírito, a comunicação e a liberdade de pensamento, de consciência e de crença. A tolerância é a harmonia na diferença. Não só é um dever de ordem ética; é igualmente uma necessidade política e jurídica. A tolerância é uma virtude que torna a paz possível e contribui para substituir uma cultura de guerra por uma cultura de paz. ${ }^{15}$

A grande dificuldade que se aborda sobre a intolerância religiosa é compreender como a pessoa que a comete, concomitantemente, não concede o direito de outrem. Todo cidadão tem a obrigação de respeitar a liberdade religiosa dos seus concidadãos. O Brasil é um país de Estado Laico, onde não existe uma religião oficial e o Estado tem que se manter neutro e imparcial diante das diferentes religiões.

Pensando no contexto brasileiro, o presente estudo não se voltará apenas para a intolerância religiosa, mas ressaltará também a liberdade religiosa prevista pela lei, como veremos no item posterior.

14 MORAES, Alexandre de. Direito Constitucional. 10.ed. São Paulo: Atlas, 2004. p. 118.

15 UNESCO. Declaração de princípios sobre a tolerância. Aprovada na $28^{a}$ Reunião da Conferência Geral da Unesco em $\quad$ Paris, em $1995 . \quad$ Disponível <http:// unesdoc.unesco.org/images/0013/001315/131524porb.pdf>. Acesso em: 13 maio 2015. 


\section{Liberdade religiosa versus intolerância}

O direito de criticar os ensinamentos de uma religião é assegurado pela liberdade de expressão, entretanto, essa crítica não deve ser pronunciada de forma desrespeitosa. A liberdade religiosa permite uma governabilidade isenta da influência de temas religiosos. Sendo essa uma liberdade protegida, não deve de forma alguma ser desrespeitada. ${ }^{16}$

Ao escolher uma religião, o ser humano está exercendo o seu livre arbítrio, assim como também está representando sua particularidade e exteriorização de seu contato entre o ser humano e o sagrado. ${ }^{17}$

A liberdade religiosa enfrentou situações adversas durante toda a história. A principal instituição que incentivou essa prática foi a própria Igreja Católica em uma complexa disputa pelo poder. ${ }^{18}$

A própria Igreja teve papel fundamental na interpretação da tolerância e da liberdade religiosa, com o Pacem in Terris, como demonstra Claude Geffré:

Tomemos o exemplo da França onde fizemos a aprendizagem, de parte a parte, tanto da parte do Estado como da parte da Igreja, do que significa uma verdadeira tolerância, após a herança difícil da Revolução vivida pelos católicos. É certo que o Vaticano II operou uma reviravolta notável, ou seja, pela primeira vez a Igreja - já na pessoa de João XXIII no momento da Pacem in Terris em 1963, e depois no concílio do Vaticano II em sua Declaração sobre a liberdade religiosa - aceitou o princípio de uma sociedade leiga, de uma sociedade pluralista, de uma sociedade que tem sua legitimidade, mesmo se essa sociedade não possui um fundamento imediatamente religioso. ${ }^{19}$

A defesa de uma liberdade religiosa tem como fator fundamental e imprescindível a viabilidade de cada pessoa adorar o seu deus, caso nenhuma dessas ações prejudique de forma direta e indireta a liberdade dos outros.

A Constituição dos países torna-se, nesse processo, um dos principais meios de proteção que trata da intolerância religiosa. Levando em consideração que o Estado aprova uma série de instrumentos que venham a permitir a tolerância religiosa.

O verdadeiro Estado Democrático de Direito tem responsabilidades diante dessa real conjuntura, tais como: o desenvolvimento das liberdades, a laicidade e a defesa da vida humana, uma vez que este Estado não deveria ser intolerante. Por isso, podemos analisar, dessa forma, que um Estado não pode ser um pouco neutro, assim como não

16 STECK, 2013.

17 BERGER, Peter. O dossel sagrado: elementos para uma teoria sociológica da religião. São Paulo: Paulus, 1985.

18 SOUZA, 1986.

19 GEFFRÉ, C. A consciência obriga. In: SAHEL, Claude. A tolerância: por um humanismo herético. Porto Alegre: L\&PM, 1993. p. 50. 
pode ser laicista. ${ }^{20} \mathrm{O}$ real significado é a proteção da dignidade da pessoa humana, como também a defesa das liberdades individuais. Quando se fala em laicidade do Estado brasileiro não se deve pensar em falta de crença, fé ou até religião, o respeito e valorização de uma fé religiosa ou expressão religiosa é favorecida no seu individual e coletivo.

Um dos maiores desafios de um país laico e democrático por direito é conscientizar a sociedade no que se refere ao respeito à liberdade religiosa de outrem, liberdade essa que se converge à tolerância, evitando assim as atitudes ofensivas a crenças e práticas religiosas quaisquer.

Legalmente, no Brasil há liberdade religiosa, partindo do princípio da laicidade e levando em consideração sua Constituição mais recente, ou seja, a Constituição de 1988. Portanto, cabe ao Estado se preocupar em possibilitar aos seus cidadãos uma situação de equilíbrio em tolerância religiosa. E esse mesmo Estado tem que garantir o livre funcionamento de todas as religiões com respeito, tolerância e compreensão. Dentro do seu território, o Estado tem a obrigação de assegurar a diversidade religiosa, possibilitando condições para uma perfeita harmonia entre as diferentes denominações religiosas. A escola, junto com a família, cumpre um papel fundamental na proteção à dignidade humana e tem a capacidade de contribuir para que o direito à liberdade religiosa não seja violado.

\section{A escola como caminho para o respeito à liberdade de crença: caminhos para a cultura de paz}

Diante de um cenário de intolerância religiosa, cujo aparato legal não responde satisfatoriamente ao apelo das minorias, pensou-se aqui na Escola como possível promotora do respeito às diferenças, contando especialmente com o apoio da família, já que, caso contrário, a Escola tem todo seu trabalho inviabilizado, pois o seio familiar detém uma influência crucial na formação das crianças e dos adolescentes.

Quando trabalhamos desde a infância sob uma perspectiva inclusiva, combatendo o bullying, damos ao nosso aluno a capacidade de refletir sobre a convivência com o outro, e isso facilita a vida dele, uma vez que esta orientação permite a existência de uma reflexão solidificada sobre o respeito a todos, independente do credo professado. Isso dá ao aluno a capacidade de ser empático com os demais e de melhor se relacionar em sociedade.

O Ensino Religioso, apesar de no cenário atual ter saído da Base Nacional Curricular, vem sendo apontado por instituições como o Fórum Nacional Permanente do

20 Conforme Cavalcanti, "o 'Laicismo' é uma ideologia de dominação estatal que desrespeita paradoxalmente os Direitos Humanos que alega defender, pois invade a Liberdade Religiosa, que é a junção entre a clássica liberdade de expressão com a defesa dos valores cosmogônicos de cada religião". CAVALCANTI, Carlos A. O que é diversidade religiosa, afinal? E você, o que tem com isso? Caminhos, Goiânia, v. 12, n. 2, p. 332-344, jul./dez. 2014. à p. 335. Disponível em: <http://seer.ucg.br/index.php/caminhos/article/viewFile/3543/2053>. Acesso em: 10 jun. 2015. 
Ensino Religioso (FONAPER) e pelos Programas de Pós-Graduação em Ciências da Religião de todo o país como sendo capaz de promover o respeito à liberdade de crenças, uma vez que no momento em que se passa a conhecer sobre as crenças mais diversas se possibilita ao discente observar os pontos em comum de suas crenças em relação às demais e abre-se espaço ainda para se observar que mesmo que seu colega não tenha nenhuma crença ele pode ser uma pessoa profundamente ética.

Muitos trabalhos acadêmicos ${ }^{21}$ apontam, inclusive, para a necessidade de as pessoas com graduação na área ocuparem estes espaços para que tal debate seja viável e, assim, seja possível a consolidação de uma discussão sólida sobre o respeito à diversidade religiosa no cenário escolar. Caso contrário, se o Ensino Religioso mantiver um cunho proselitista, este cenário estará fadado ao fracasso, pois promoverá um ambiente hostil às diferenças e promotor apenas de divulgação de um credo consensual, legitimando uma maior discriminação em relação às minorias.

É preciso se promover o respeito às diferenças desde a infância para que não haja necessidade sequer de acionar o aparato legal, já que a partir da sala de aula e do apoio dos pais estas questões já seriam internalizadas pelos alunos e, assim, estaria consolidada a ideia de que é preciso respeitar todas as crenças. Não se pode deixar de destacar aqui o trabalho atual de professores ${ }^{22}$ que vêm agindo dessa forma e contribuindo para promoção de uma cultura de paz.

\section{Considerações finais}

Pensar a intolerância religiosa no contexto brasileiro, a partir de suas leis e concepções, permite ao leitor uma reflexão sobre a necessidade urgente de que este debate seja fomentado pela sociedade.

O respaldo legal que temos hoje é reflexo dos casos recorrentes de ações de intolerância religiosa, principalmente com os cultos afro, e é por isso que estes tiveram

21 Veja-se: BRASILEIRO, Marislei S. E. Ensino religioso na escola: o papel das ciências das religiões. Tese (Doutorado em Ciências da Religião) - Programa de Pós-Graduação em Ciências da Religão, Pontifícia Universidade Católica de Goiás, Goiânia, 2010; SILVA, Gracileide A. O ensino religioso na Paraíba: desafios na formação docente e no contexto educacional. Dissertação (Mestrado em Ciências das Religiões) Programa de Pós-Graduação em Ciências da Religião, Universidade Federal da Paraíba, João Pessoa, 2009.

22 Os trabalhos de Gilton Abreu, Débora Almeira e Maria Coelho fazem alusão a essas experiências diferenciadas. ABREU, Gilton. O ensino religioso como instrumento para minimizar as desigualdades sócioeducacionais no contexto escolar. Dissertação (Mestrado em Teologia) - Programa de Pós-Graduação em Teologia - Faculdades EST, São Leopoldo, 2009; ALMEIDA, Débora V. C. B. Ensino religioso ou ensino sobre religiões? A concepção de Ensino religioso escolar no Estado de São Paulo. Dissertação (Mestrado em Ciências da Religião) - Programa de Pós-Graduação em Ciências da Religião, Pontifícia Universidade Católica de São Paulo, São Paulo, 2006; COELHO, Maria Efigênia. Educação e Religião como elementos para a superação da Intolerância Religiosa: integração e relação na compreensão do Ensino Religioso. Dissertação (Mestrado em Teologia) - Programa de Pós-Graduação em Teologia, Faculdades EST, São Leopoldo, 2009. 
lugar de destaque nesta pesquisa ao discutirmos um item específico sobre suas leis e especificidades.

Esse estudo teve o intuito de mostrar através das constatações o processo da intolerância religiosa ainda presente na atualidade, relacionadas às religiões de origens africanas, sendo fundamental levar à tona as preocupações que essa intolerância causa, como também, as atitudes que são expressas por gestos e palavras.

O diálogo fecundo entre o combate à intolerância religiosa e a liberdade religiosa é complementar nesta discussão, pois ao passo que promovemos um debate contrário ao desrespeito às religiões, o significado da relevância da liberdade de credo presente na Constituição Brasileira precisa ser pensado.

A Escola como um caminho profícuo de estímulo para esta promoção da paz é pensada neste artigo como forma de ir além da problematização sobre um cenário complexo de intolerância religiosa no país, pois reflete sobre novas possibilidades de mudanças deste cenário atual.

Sendo o Brasil um estado laico e cuja pluralidade religiosa está no cerne de suas raízes, podemos considerar este estudo como capaz de colaborar com a discussão, à medida que apresenta o cenário atual do país, suas leis, estudos recentes e vê na Escola um caminho desta discussão se tornar algo concreto.

\section{Referências}

ABREU, Gilton. O ensino religioso como instrumento para minimizar as desigualdades sócioeducacionais no contexto escolar. Dissertação (Mestrado em Teologia) - Programa de PósGraduação em Teologia - Faculdades EST, São Leopoldo, 2009.

ALMEIDA, Débora V. C. B. Ensino religioso ou ensino sobre religiões? A concepção de Ensino religioso escolar no Estado de São Paulo. Dissertação (Mestrado em Ciências da Religião) Programa de Pós-Graduação em Ciências da Religião, Pontifícia Universidade Católica de São Paulo, São Paulo, 2006.

BERGER, Peter. O dossel sagrado: elementos para uma teoria sociológica da religião. São Paulo: Paulus, 1985.

BRASIL. Casa Civil. Subchefia para Assuntos Jurídicos. Constituição da República do Brasil. Disponível em: <http://www.planalto.gov.br/ccivil_03/constituicao/constituicao.htm>. Acesso em: 25 set. 2015.

. Lei n. 12.288, de 20 de julho de 2010. Estatuto da Igualdade Racial. Disponível em: <http://www.planalto.gov.br/ccivil_03/_ato2007-2010/2010/lei/112288.htm>. Acesso em: 02 out. 2015.

Lei n. 9.459, de 13 de maio de 1997. Disponível em:

<http://www.planalto.gov.br/ccivil_03/leis/L9459.htm>. Acesso em: 01 out. 2015. 
BRASILEIRO, Marislei S. E. Ensino religioso na escola: o papel das ciências das religiões. Tese (Doutorado em Ciências da Religião) - Programa de Pós-Graduação em Ciências da Religão, Pontifícia Universidade Católica de Goiás, Goiânia, 2010.

CAVALCANTI, Carlos A. O que é diversidade religiosa, afinal? E você, o que tem com isso? Caminhos, Goiânia, v. 12, n. 2, p. 332-344, jul./ dez. 2014. Disponível em: <http://seer.ucg.br/index.php/caminhos/article/viewFile/3543/2053>. Acesso em: 10 jun. 2015.

CHAVES, L. G. Mendes. Minorias e seu estudo no Brasil. Revista de Ciências Sociais, Fortaleza, v. 1, n. 1, p. 149-168, 1970. Disponível em:

<http://www.repositorio.ufc.br/handle/riufc/4487>. Acesso em: 01 ago. 2017.

COELHO, Maria Efigênia. Educação e Religião como elementos para a superação da Intolerância Religiosa: integração e relação na compreensão do Ensino Religioso. Dissertação (Mestrado em Teologia) - Programa de Pós-Graduação em Teologia, Faculdades EST, São Leopoldo, 2009

FERREIRA, Aurélio Buarque de Holanda. Dicionário Aurélio básico da Língua Portuguesa. Rio de Janeiro: Nova Fronteira, 1988.

GEFFRÉ, C. A consciência obriga. In: SAHEL, Claude. A tolerância: por um humanismo herético. Porto Alegre: L\&PM, 1993.

MORAES, Alexandre de. Direito Constitucional. 10.ed. São Paulo: Atlas, 2004.

ORGANIZAÇÃO DAS NAÇÕES UNIDAS. Declaração Universal dos Direitos Humanos (1948). Disponível em: < http://www.dudh.org.br/wpcontent/ uploads/2014/12/dudh.pdf>. Acesso em: 19 jul. 2015.

ROCHA, José G. A intolerância religiosa e religiões de matrizes africanas no Rio de Janeiro. Revista África e Africanidades, ano IV, n. 14/15, ago./nov. 2011. Disponível em: <www.africaeafricanidades.com>. Acesso em: 05 jul. 2015.

SILVA, Gracileide A. O ensino religioso na Paraíba: desafios na formação docente e no contexto educacional. Dissertação (Mestrado em Ciências das Religiões) - Programa de Pós-Graduação em Ciências da Religião, Universidade Federal da Paraíba, João Pessoa, 2009.

SILVA, M. V. “Liberdade, Democracia e Intolerância Religiosa”. In: SANTOS, I.; ESTEVES FILHO, A. (Orgs). Intolerância Religiosa X Democracia. Rio de Janeiro: CEAP, 2009. p. 125143.

SOUZA, Laura M. O diabo e a Terra de Santa Cruz. São Paulo: Companhia das Letras, 1986. 
STECK, Juliana. Intolerância religiosaé crime de ódio e fere a dignidade. Disponível em <http://www12.senado.gov.br/jornal/edicoes/2013/04/16/intolerancia-religiosa-ecrime-de-odio-e-fere-a-dignidade>. Acesso em: 10 jul. 2015.

TOKARNIA, Mariana. Negros e religiões africanas são os mais discriminados, mostra Disque 100. Disponível em: <http://agenciabrasil.ebc.com.br/direitos-humanos/noticia/201507/negros-e-religioes-africanas-sao-os-que-mais-sofrem-discriminacao >. Acesso em: 10 set. 2015.

UNESCO. Declaração de princípios sobre a tolerância. Aprovada na $28^{a}$ Reunião da Conferência Geral da Unesco em Paris, em 1995. Disponível em: <http://unesdoc.unesco.org/images/0013/001315/131524porb.pdf>. Acesso em: 13 maio 2015. 